\title{
Experimental and Numerical Analysis of an Innovative Mixer Geometry for Urea Injection in SCR Applications
}

\author{
Federico Millo ${ }^{1}$ (D) Francesco Sapio $^{1} \cdot$ Benedetta Peiretti Paradisi $^{1} \cdot$ Andrea Bianco $^{2} \cdot$ Lucio Postrioti $^{3}$. \\ Giacomo Buitoni ${ }^{4} \cdot$ Marco Tabarrini $^{4} \cdot$ Cristina Robino $^{5}$
}

Received: 2 November 2021 / Revised: 6 January 2022 / Accepted: 7 January 2022 / Published online: 5 February 2022

(c) The Author(s) 2022

\begin{abstract}
Selective catalytic reduction (SCR), based on the injection of urea-water-solution (UWS), is one of the prevailing and more effective approaches to reduce NOx emissions in diesel engines. To improve the performance and durability of the system, it is crucial to develop reliable simulation tools able to correctly describe not only the urea conversion into ammonia and the mixing with exhaust gases but also the possible formation of solid deposits along with the engine's exhaust line.

In the present paper, two different exhaust systems for off-road applications are analyzed, both of them consisting of a diesel oxidation catalyst (DOC) followed by a diesel particulate filter (DPF), a UWS injection and a mixing device, and an SCR catalyst. Two alternative UWS mixing subsystems are evaluated, including a newly developed design. A 3D-CFD numerical analysis is carried out to assess the performance of both systems in terms of pressure drop, UWS spray, and liquid film development, in addition to flow velocities and species concentration uniformities at SCR catalyst inlet. A detailed analysis of droplet impingement on walls and liquid film development is enabled, thanks to a conjugate heat transfer (CHT) approach. Moreover, a deposit risk index is used to identify the areas of the systems where urea deposit formation is expected.

Eventually, numerical results are compared with experiments on one operating condition chosen as the most challenging in terms of exhaust temperature and flow rate, both in terms of systems $\mathrm{NO}_{\mathrm{x}}$ conversion efficiency and deposit formation, showing a satisfactory agreement, thus paving the way to use the proposed synergetic numerical and experimental approach to further optimize the design and the system's performance.
\end{abstract}

Keywords Off-road diesel aftertreatment $\cdot$ Selective catalytic reduction NOx $\cdot$ Urea water solution mixer geometry $\cdot$ Solid deposit formation

\section{Introduction}

European standards for off-road diesel engines have become gradually more stringent in terms of both particulate matter $(\mathrm{PM})$ and $\mathrm{NO}_{\mathrm{x}}$ emissions. In particular, the stage IV standards introduced in 2010, a $\mathrm{NO}_{\mathrm{x}}$ limit of $0.4 \mathrm{~g} / \mathrm{kWh}$, were confirmed in 2016 with the stage $\mathrm{V}$ legislation, widening

Federico Millo

federico.millo@polito.it

Energy Department, Politecnico di Torino, 10129 Torino, Italy

2 POWERTECH Engineering, 10127 Torino, Italy

3 Università degli Studi di Perugia, 06125 Perugia, Italy

4 Shot To Shot Engineering, 06134 Perugia, Italy

5 Cornaglia Group, 10095 Grugliasco, TO, Italy the scope of regulated diesel engines including previously unregulated engines with power below $19 \mathrm{~kW}$ and above $560 \mathrm{~kW}$.

Widespread adoption of $\mathrm{NO}_{\mathrm{x}}$ after-treatment systems (ATS) has been triggered, and urea-selective catalytic reduction (SCR) has become the mainstream approach for $\mathrm{NO}_{\mathrm{x}}$ mitigation [1]. In this type of system, urea-water-solution (UWS) is injected into the exhaust gases, undergoes the atomization and evaporation processes, and decomposes to a mixture of ammonia, iso-cyanic acid, and other species. The mixture reacts with the exhaust flow in the SCR catalyst to abate $\mathrm{NO}_{\mathrm{x}}$ emissions. However, if UWS decomposition remains incomplete, solid urea and other by-products could be responsible for the formation of crystals, which remain as deposits in the exhaust system. The presence of deposits results in an inefficient use of urea, with a consequent low catalyst conversion efficiency and corrosion of stainless 
steel. Besides the direct conversion penalties, solid deposits can seriously affect both the spray development and the spray-mixer interaction, causing further inefficiencies in the $\mathrm{NO}_{\mathrm{x}}$ conversion process [2]. Moreover, the formation of urea deposits could potentially increase overall PM emissions [3].

Different factors contribute to the formation of urea deposits, such as the level of exhaust temperature and flow rate [4], UWS injection strategy and configuration [5], or the dynamics of the impingement on wall and mixer surfaces [6]. In particular, if the wall temperatures remain below the nonwetting threshold, the impingement of UWS on mixer surfaces leads to liquid film formation, with the risk of urea solid deposition. In this context, experimental and numerical synergy is necessary to optimize the process leading to the availability of $\mathrm{NH}_{3}$ at the catalyst entrance, understanding the mixing and impingement dynamics occurring in the UWS sprays [7]. Indeed, the distribution of $\mathrm{NH}_{3}$ at the inlet of the SCR catalyst could provide an indirect indication of the de- $\mathrm{NO}_{\mathrm{x}}$ efficiency of the system [8].

The optimization of the SCR system performance could be affected by the packaging design [9] and specific adaptation of UWS mixers to a given exhaust system is necessary to mitigate the risk of deposit formation [10]. Therefore, high-performance SCR systems require a properly designed UWS mixing section, to obtain an efficient urea-to-ammonia conversion, a well-distributed ammonia flow on the SCR catalyst and to avoid urea deposit formations along with the ATS $[11,12]$. Due to the significant impact of the system layout on deposit formation, a validated 3D-CFD simulation approach could be exploited, also in the ATS design phase, to predict the regions where the risk of urea deposit is present, ahead of experimental campaigns.

Improvements in numerical simulations have been made to predict the process of urea thermo-hydrolysis [13], and detailed decomposition mechanisms of urea have been implemented successfully to properly simulate the deposit formation process $[14,15]$. However, the inclusion of a detailed chemical scheme to simulate UWS decomposition could properly predict the urea by-product formation and consequently the deposit build-up, but with high penalties in terms of computational cost. Furthermore, another aspect to be considered to describe the deposit formation process is the influence of wall temperature variations [16].

The present work proposes a cost-effective simulation methodology to characterize the performance of different UWS mixer subsystems. A simplified model to describe the UWS decomposition is implemented, together with a deposit risk index defined through an empirical approach based on the liquid film properties to identify the area where a high risk of deposition is expected [12]. A conjugate heat transfer (CHT) approach is applied to resolve the transient and non-uniform distribution of the temperature field on mixer walls. In particular, two diesel ATS designed for an off-road application are investigated. The systems are both composed of a diesel oxidation catalyst (DOC), with a subsequent diesel particulate filter (DPF), and a SCR catalyst, and they differ only for the UWS mixer geometry inserted upstream of the SCR inlet. An extensive experimental campaign has been conducted to evaluate the mixing section efficacy both in terms of $\mathrm{NO}_{\mathrm{x}}$ conversion efficiency and urea deposit formation. The numerical methodology has been validated in one operating condition of the exhaust system, comparing the results in terms of system $\mathrm{NO}_{\mathrm{x}}$ conversion efficiency and deposit formation prediction. In more detail, the steadystate conversion efficiency calculated from the experimental data for the two systems has been compared with the $\mathrm{NH}_{3}$ distributions measured upstream of the SCR catalyst in the 3D-CFD simulation. Then, acquired pictures at different depths inside the two mixers showing the presence of solid deposits have been compared with the area where the simulation highlights the presence of deposit risk.

The combination of the experimental and numerical analyses could be seen as a powerful tool to characterize the UWS evolution, liquid film development, species concentrations and velocity uniformity at the SCR catalyst inlet section, and to provide optimization hints, concerning the UWS mixing system design, to further improve the system's performance.

\section{Test Case Description}

In the present work, two different exhaust systems are analyzed; each of them composed of a DOC, a DPF and an SCR. Figure 1 displays the virtual representation of the complete system comprehensive of all the common parts between the two geometries. The $z$-axis is parallel to the exhaust system development, while the $y$-axis is parallel to the exhaust flow from the engine outlet. The difference between the two geometries is limited to the injection and mixing subsystem placed between the DPF and the SCR.

In particular, Fig. 2 represents the baseline design (geometry A) of the UWS mixing system. Two wings placed upstream of the UWS injector, highlighted in blue in the figure, create a swirling flow in the exhaust gases coming from the DPF to the SCR and enhance the mixing. Geometry A is characterized by opposite directions of gas and UWS spray, as highlighted in Fig. 2. A modified version of the mixer design (geometry B) is presented in Fig. 3 and it is composed of a static mixer with a series of radial openings. The peculiar design of geometry B aims to deflect the exhaust gases and generate optimal vorticity in the gas flow, to promote the formation of a homogeneous $\mathrm{NH}_{3}$ distribution upstream of the SCR inlet. It is worth highlighting that geometry B is characterized by concurrent directions of gas and UWS spray development. 
Fig. 1 Virtual representation of the complete exhaust system

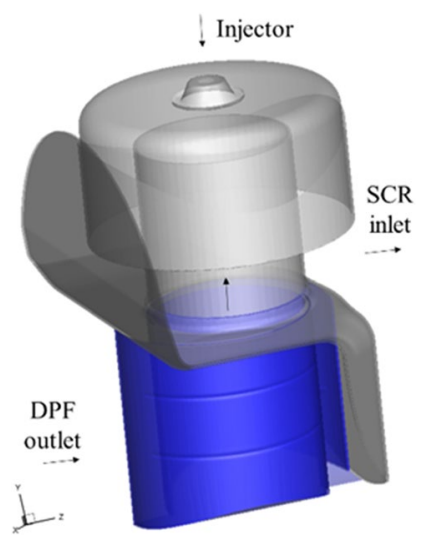

Fig. 2 UWS mixing subsystem for geometry A

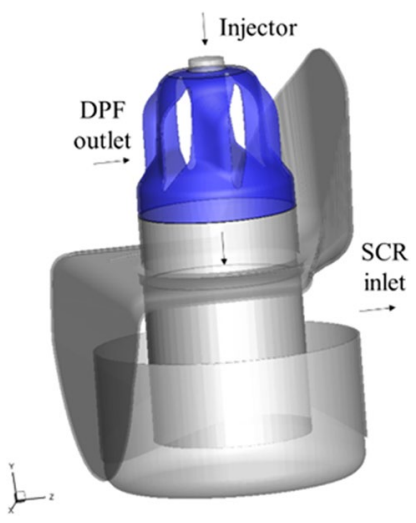

Fig. 3 UWS mixing subsystem for geometry B

Three different operating conditions have been considered for the experimental analysis, in terms of exhaust mass flow rate and temperature, as can be seen in Table 1 . In particular, $\mathrm{NH}_{3}$ values reported in Table 1 refer to the amount of ammonia theoretically available at SCR catalyst assuming a complete conversion of the injected urea-water solution. In addition, it is worth mentioning that no $\mathrm{NO}_{2}$ was considered in the experiments to avoid possible issues related to $\mathrm{NO}_{2}$ conditioning and mixing with other gases.

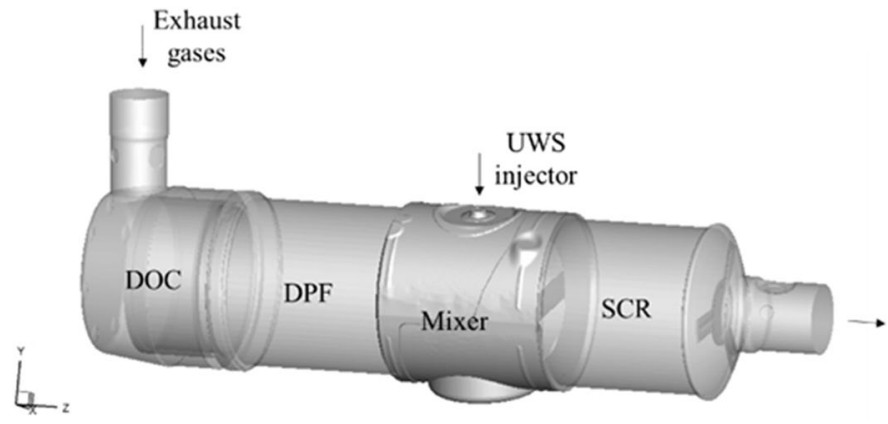

The range of analyzed exhaust temperatures and flow rates is typical of the present off-road application, and it has been considered challenging in terms of mixing capability of the system. Indeed, at low flow rates, the exhaust gases are not able to create sufficient swirl motion and turbulence to avoid the impingement of the urea droplets on the mixer walls, potentially enhancing solid deposit formation. Test case 1 has been also analyzed through a 3D-CFD simulation approach.

\section{Experimental Analysis}

SCR efficiency and urea deposit evaluation analysis have been performed at STSe laboratory. In the following paragraph, a brief description of the experimental setup and the adopted procedures is reported.

\subsection{Experimental Setup Description}

SCR efficiency analysis and urea deposit evaluation have been performed using the STSe hot flow bench (HFB), a test bench that can reproduce the flow rate, temperature, and $\mathrm{NO}_{\mathrm{x}}$ pollutant composition of a diesel engine to analyze and optimize all the aftertreatment components. Figure 4 represents a sketch of the considered HFB. It consists of a side-channel blower, a laminar flow meter, a regenerative tube and shell heat exchanger, an electric heater, and a reconfigurable test section. Mass flow rate and temperature ranges can reach about $800 \mathrm{~kg} / \mathrm{h}$ and $600^{\circ} \mathrm{C}$ with a maximum 1.4 bar absolute pressure at the test section inlet. The HFB guarantees complete flexibility in terms of ATS operating conditions, pollutant compositions ( $\mathrm{NO}$ and $\mathrm{NO}_{2}$ are dosed separately from pure-gas bombs), flow rate $\left( \pm 1 \mathrm{~m}^{3} / \mathrm{h}\right.$ accuracy), temperature $\left( \pm 2{ }^{\circ} \mathrm{C}\right), \mathrm{UWS} / \mathrm{NO}_{\mathrm{x}}$ ratio, and diesel exhaust fluid (DEF) injection strategy.

The airflow rate is controlled by a laminar flow meter (Meriam Instruments 50-MC2-4) upstream of the blower along with air temperature, absolute pressure, and humidity. Pollutant flow rates are independent of hot air flow/ 
Table 1 Selected operating conditions of the exhaust system

\begin{tabular}{llllll}
\hline Test case & $\begin{array}{l}\text { Inlet mass flow } \\
\text { rate }[\mathrm{kg} / \mathrm{h}]\end{array}$ & Inlet temp. $\left[{ }^{\circ} \mathrm{C}\right]$ & NO in $[\mathrm{ppm}]$ & $\begin{array}{l}\mathrm{NO}_{2} \text { in } \\
{[\mathrm{ppm}]}\end{array}$ & $\begin{array}{l}\mathrm{Theor} . \\
\mathrm{NH}_{3} \text { in } \\
{[\mathrm{ppm}]}\end{array}$ \\
\hline Test case 1 & 125 & 250 & 1250 & 0 & 1380 \\
Test case 2 & 125 & 300 & 1715 & 0 & 1885 \\
Test case 3 & 135 & 350 & 2550 & 0 & 2800 \\
\hline
\end{tabular}

temperature and they are regulated by separate hot wire flow controllers for $\mathrm{NO}$ and $\mathrm{NO}_{2}$ species (Bronkhorst Mini Flow). Injection pressure, frequency, and actuation time are set to control UWS injection, which mass flow rate is continuously measured by a Coriolis flowmeter (Siemens Sitrans MassFlow 2100). Exhaust gas species concentrations, in particular $\mathrm{NO}, \mathrm{NO}_{2}, \mathrm{~N}_{2} \mathrm{O}, \mathrm{NH}_{3}, \mathrm{CO}, \mathrm{CO}_{2}, \mathrm{H}_{2} \mathrm{O}$, and $\mathrm{HCNO}$, are continuously acquired by an AVL Sesam i60 FTIR (with $1 \%$ accuracy). The gas sampling collection point is typically placed downstream of the complete SCR system. Original equipment manufacturer (OEM) $\mathrm{NO}_{x} / \mathrm{NH}_{3}$ cross sensitive sensors can be installed in different positions, acquired and compared with the reference FTIR output. Temperature and differential pressure between ATS's components are continuously monitored to evidence any eventual mixer o SCR clogging. Figure 5 displays different pictures of the SCR converter instrumentation.

In addition to this, the STSe HFB is equipped with an apparatus for the evaluation of urea deposit mass, based on a high accuracy balance (Radwag PM25.C32, accuracy \pm $0.1 \mathrm{~g})$ that allows the deposit mass evaluation maintaining the ATS at high temperature $\left(180^{\circ}\right)$. This approach guarantees higher accuracy in urea deposit evaluation than other weighting procedures executed after the ATS test with the system weighted at ambient condition, avoiding any absorption of chemical species by the ATS catalysts due to condensation. STSe HFB is managed by a proprietary control system developed in LabVIEW.

\subsection{Test Procedure}

The main HFB output consists of the process time-history (1 s sampling period), including airflow rate, pressure, temperature in different positions along with the tested system, UWS flow rate, and gas species concentration downstream the converter tested. In terms of analyzed species concentrations, a typical HFB output is reported at the top of Fig. 6, where the start of the UWS injection is assumed as timing zero. $\mathrm{NO}_{\mathrm{x}}$ conversion efficiency analysis and urea deposit evaluation tests are divided into four phases:

Phase (A) system stabilization (Fig. 6.1): Once the chosen system flow rate and temperature are reached, the required
$\mathrm{NO}$ and $\mathrm{NO}_{2}$ flows are injected to obtain the required pollutant concentration, without UWS injection. The last 60 $\mathrm{s}$ of this stabilization period represents the test condition reference.

Phase (B) $N O_{x}$ conversion efficiency test (Figs. 6.2 and 6.3): UWS injection starts with the prescribed $\mathrm{NH}_{3} / \mathrm{NO}_{\mathrm{x}}$ ratio at time 0 ; the effective final conversion efficiency reached by ATS (Eq. 1) is determined once a stability criterion based on $\mathrm{NH}_{3}$ stabilization factor (Eq. 2) for the residual $\mathrm{NO}_{\mathrm{x}}$ and $\mathrm{NH}_{3}$ is fulfilled. All the concentrations in the following equations are expressed by volume. The system conversion efficiency curve is computed as in Eq. 1:

$\operatorname{Eff}(\%)=100 * \frac{\overline{N O_{x, \text { in }}}-\overline{N O_{x, \text { out }}}}{\overline{N O_{x, \text { in }}}}$,

where $\overline{N O_{x, \text { in }}}$ and $\overline{N O_{x, \text { out }}}$ are, respectively, the measured $\mathrm{NO}_{\mathrm{x}}$ concentration (as the sum of NO and NO2) at the SCR system inlet and outlet. The stabilization factor for the $\mathrm{NH}_{3}$ is defined in Eq. (2):

$\mathrm{NH}_{3}$ stabilization factor $=\frac{\frac{N H_{3, \text { miss }}}{N H_{3, i n j} i}-\frac{N H_{3, m i s s}}{N H_{3, i n j}}{ }_{i+300}}{5} \leq 0.005$,

where $i$ indicates the considered time after the start of UWS injection and the $\mathrm{NH}_{3, \text { inj }}$ ammonia which is theoretically obtainable from UWS injected. $\mathrm{NH}_{3, \text { miss }}$ represents the ammonia unbalanced computed in Eq. (3):

$\mathrm{NH}_{3, \text { miss }}=\mathrm{NH}_{3, \text { inj }}-\left(\mathrm{NH}_{3, \text { out }}+\mathrm{NH}_{3, \text { used for conversion }}\right)$,

where $\mathrm{NH}_{3}$, out is the $\mathrm{NH}_{3}$ concentration measured at the SCR system outlet (so-called ammonia slip) and $\mathrm{NH}_{3}$, used for conversion is the $\mathrm{NH}_{3}$ theoretical concentration actually used to convert $\mathrm{NO}_{\mathrm{x}}$.

Phase (C) ammonia storage test (Fig. 6.3): UWS injection is stopped, while $\mathrm{NO}$ and $\mathrm{NO}_{2}$ insertion is maintained at the same rate of phases $\mathrm{A}$ and $\mathrm{B}$. This phase allows computing the ammonia storage effectively accumulated in the SCR catalyst during phase B. Ammonia storage is evaluated in terms of theoretical ammonia storage $\mathrm{NH}_{3, t h}$ (Eq. 4) and Actual ammonia storage $\mathrm{NH}_{3, \text { act }}$ (Eq. 5) as the cumulative contributions of all the $j$ time steps of equal $d t$ duration during the efficiency test: 
Fig. 4 STSe hot flow bench

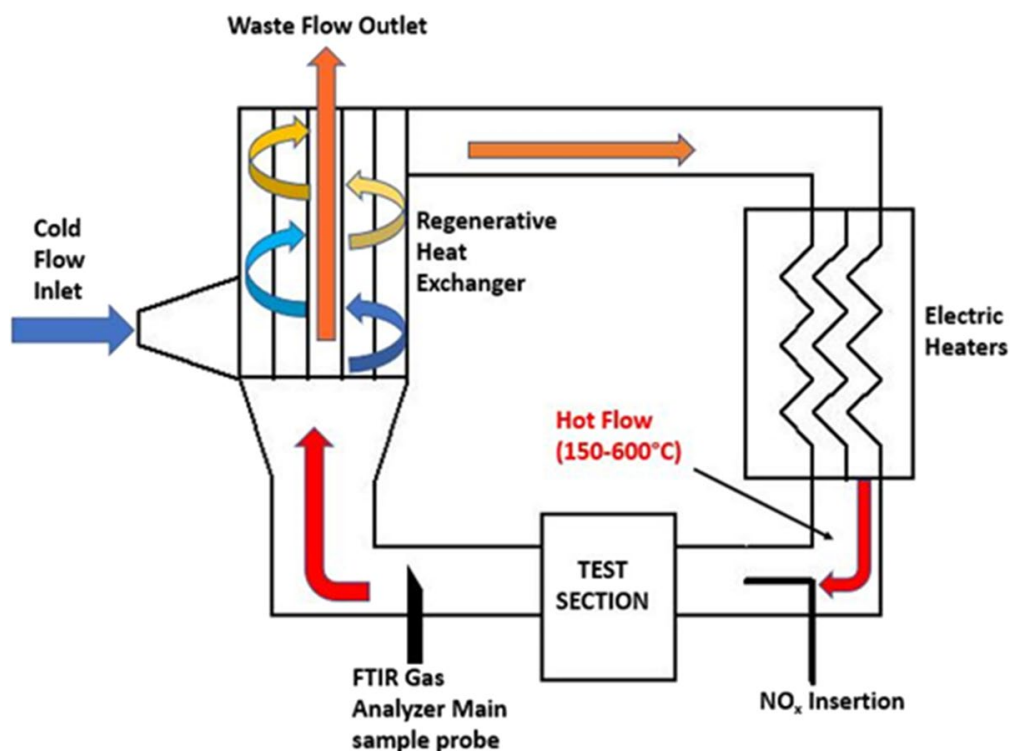

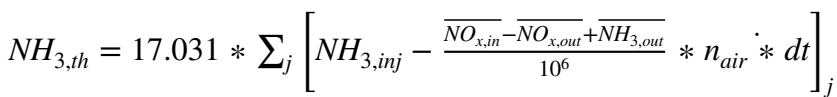

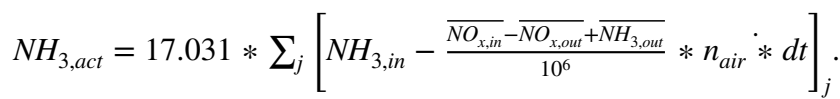

(4)
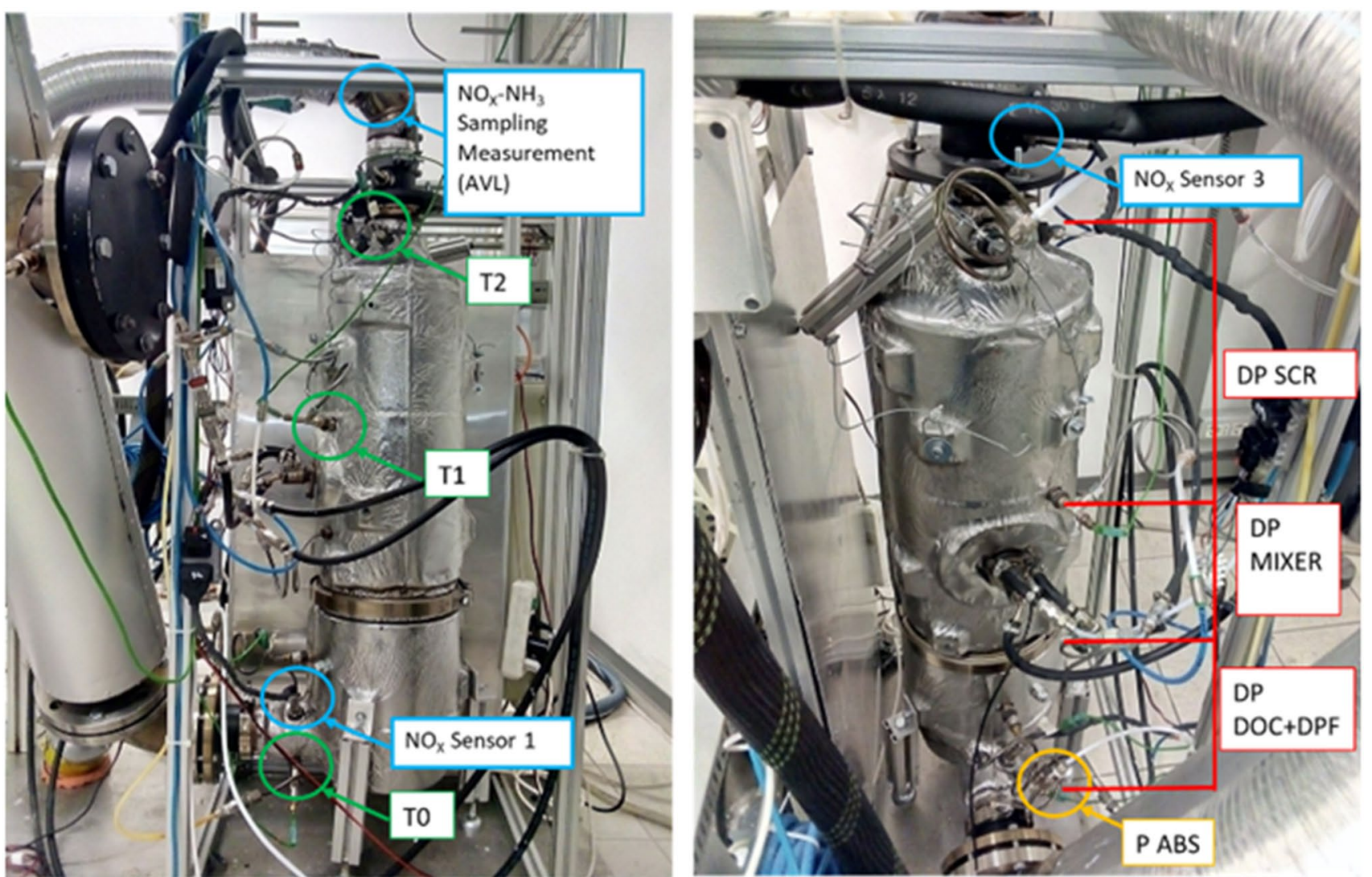

Fig. 5 SCR converter instrumentation 

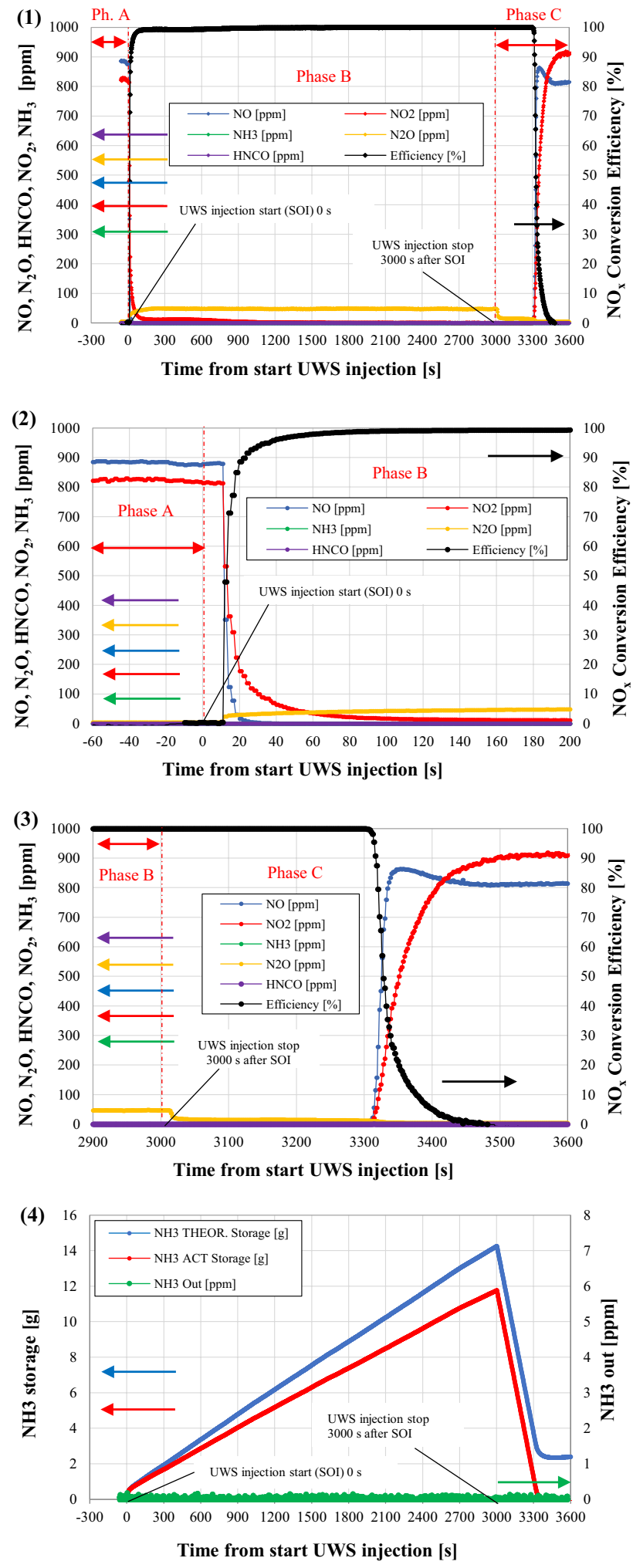

Fig. 6 STSe Hot HFB time history output data, measurements taken at the SCR outlet. Single test phases zoom (phase A, B, top) and ammonia storage (phase $\mathrm{C}$, bottom)
The theoretical mass of ammonia stored is computed, according to Eq. 2, as the mass balance for $\mathrm{NO}_{\mathrm{x}}$ reduction reactions in an SCR system, where theoretically, the entire UWS mass injected is assumed as completely converted to gaseous ammonia. Unfortunately, this conversion process often cannot be assumed as complete, especially at low temperature operating conditions and using compact ATS layouts, in which the urea residence time is short. As a consequence, the stored ammonia mass evaluated as $\mathrm{NH}_{3, t h}$ could be overestimated in comparison with the effective quantity stored by the catalyst.

Ammonia storage test phase $\mathrm{C}$ allows calculating the ammonia stored more realistically (Eq. 5); during this test, the phase executed without UWS injection, only the ammonia effectively stored in the SCR catalyst, can react with the incoming $\mathrm{NO}_{\mathrm{x}}$. The ammonia present in the catalyst at the end of phase B (effectively stored) can be evaluated as the time-integral of the ammonia balance time-history during the following phase C. $\mathrm{NH}_{3, a c t}$ is evaluated as the sum of the ammonia mass reacting in each time interval $d t$ (computed based on the $\mathrm{NO}_{\mathrm{x}}$ concentration decrease in the catalyst) and the slipped ammonia. Phase $\mathrm{C}$ ends when the SCR catalyst runs out of his ammonia storage, i.e., when the $\mathrm{NO}_{\mathrm{x}}$ concentration exiting by the ATS matches the $\mathrm{NO}_{\mathrm{x}}$ injected by the HFB pollutant dosing system.

Phase (D) urea deposit evaluation: The weighing process is executed using the following procedure:

1. The ATS is weighed hanging it on a hook at the balance bottom, with all pipes and cables disconnected; AdBlue (and eventually cooling fluid) pipes and injector are maintained pressurized during this procedure using valves.

2. Before the test, the clean ATS is heated at $200^{\circ} \mathrm{C}$. When its temperature is stable, it is released from the HFB and during its cool-down phase, it is weighed once it reaches $180^{\circ} \mathrm{C}$, according to point 1 ). This measured mass is assumed as the ATS tare.

3. The ATS is tested at the prescribed flow and temperature conditions. Once the test is finished, it is again cooled to $180{ }^{\circ} \mathrm{C}$ and weighed as described in point 1 ).

The difference between the two values obtained in points (2) and (3) represents the effective deposits accumulated inside the ATS during the test. Applying this procedure, the ATS tare can be confirmed after a deposits clean-up phase at high temperature; in our tests, the ATS tare must be verified before each new operating condition, with a repeatability of $( \pm 0.5 \mathrm{~g})$. This way, reliable results in terms of mass deposit formation in given operating conditions can be obtained, maintaining the ATS at a controlled temperature $\left(180^{\circ} \mathrm{C}\right.$ $\pm 5^{\circ} \mathrm{C}$ ), preventing humidity and other species' significant condensation in the catalysts, and altering the measure. 
Furthermore, endoscopic videos and images of ATS internal surfaces are acquired to define where the deposits are located. For every tested operating condition, a series of internal pictures is acquired using a cylindrical coordinate approach to correlate deposit pictures to CFD results, see Figs. 7 and 8. Mixer internal zones are explored by entering with the endoscope from the UWS injector fixture, rotating the camera along the mixer axis with $60^{\circ}$ steps in three virtual planes located at different distances (depths) from the UWS nozzle tip (geometry A: 50 and $109 \mathrm{~mm}$, geometry B: 18, 55 and $109 \mathrm{~mm}$ ) as visible in Figs. 7 and 8. Going ahead, the ATS has to be cleaned by operating the HFB as simulating an engine regeneration phase at high temperature and medium flow rate.

\section{Numerical Analysis}

To investigate the root causes of peculiar SCR system performances, 3D-CFD analyses have been carried out using the commercial software CONVERGE CFD v2.4 [17]. In particular, the different mixers' geometries and flow configuration affect the vorticity distribution of the exhaust gases, the UWS spray evolution, and consequently the mixing process as well as the uniformity of flow and species concentration at the SCR inlet. Liquid film development and urea deposit formation are influenced as well by the geometries of the mixers. In this context, numerical analyses can be considered complementary to the experimental campaign, since they allow to obtain additional information concerning the phenomena happening within the exhaust lines, which cannot be acquired during experimental tests, providing useful insights on the key aspects influencing $\mathrm{NO}_{\mathrm{x}}$ conversion efficiency and deposit formation.
Simulations were performed considering the whole aftertreatment system and the two different mixing subsystems. The operating conditions considered featured an inlet mass flow rate of $125 \mathrm{~kg} / \mathrm{h}$ and a fixed temperature of $250{ }^{\circ} \mathrm{C}$, corresponding to test case 1 of the experimental campaign (Table 1). Preliminary steady-state single-phase simulations were performed to calculate gas flow field and pressure drops within the systems and initialize multi-phase transient simulations, which were then used to investigate UWS spray development, liquid film formation, and $\mathrm{NH}_{3}$ mixing. In particular, since the aim of the numerical analysis was the characterization of the systems in terms of flow uniformity and mixing between the exhaust gases and the UWS, the inlet gas composition was set to represent air, and $\mathrm{NO}_{\mathrm{x}}$ emissions have not been included. Consequently, all the reactions inside the SCR systems were not modeled in the numerical simulations. The DOC, DPF, and SCR catalysts have been modeled as porous regions in the numerical analysis, and the pressure loss coefficients have been calibrated to match the available experimental data in terms of pressure losses inside each component. The virtual representation of the DOC has been further simplified substituting the real perforated plate element with a dedicated porous region of 5-mm thickness.

An inflow boundary condition was used to represent engine exhaust gases entering the exhaust line, with constant values of mass flow rate and temperature. A turbulence intensity equal to $10 \%$ has been assumed on the inflow boundary, with a turbulence length scale representing a fully developed flow condition. Regarding the outlet boundary of the system, a constant static pressure of 1 bar has been imposed. Following this approach, the inlet pressure of the system remained unconstrained and dependent on the pressure losses inside the system. As far as thermal boundaries are concerned, details are provided in section 4.2 of the paper.
Fig. 7 Urea deposits imaging adopted approach: UWS housing endoscope entering point and reference for cylindrical coordinates theta angle (left) and planes of acquisition (right) for geometry A
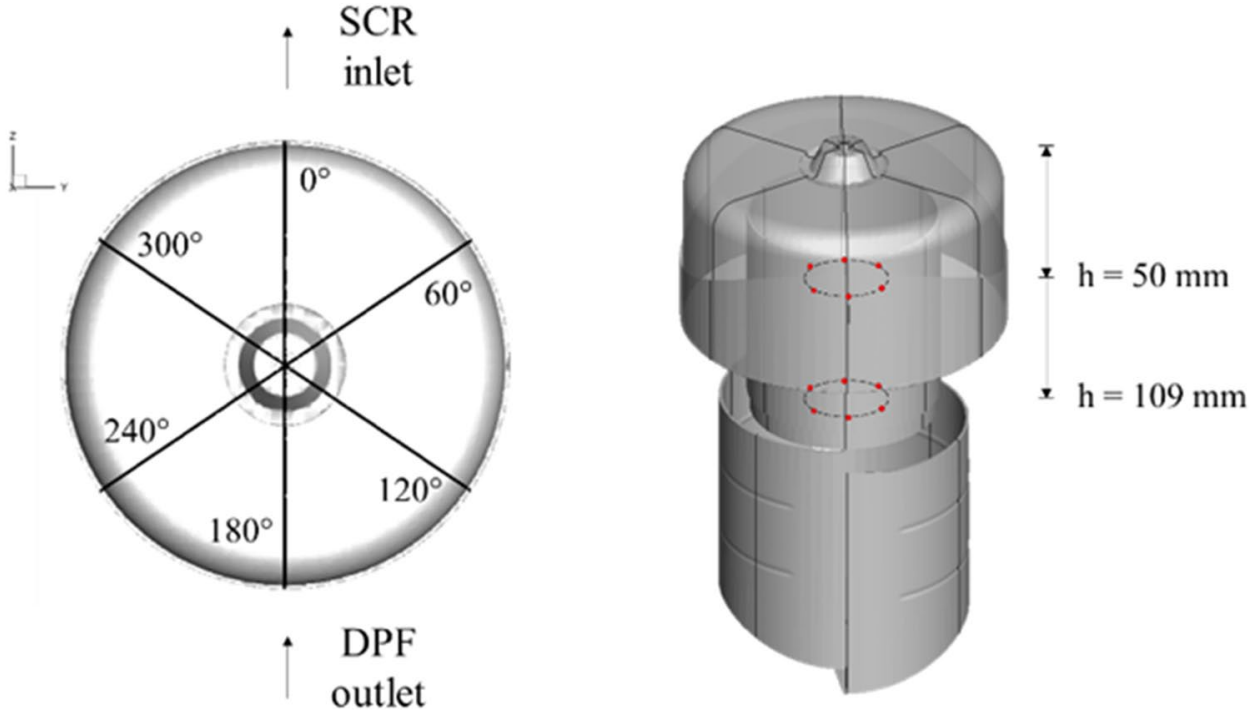
Fig. 8 Urea deposit imaging adopted approach: UWS housing endoscope entering point and reference for cylindrical coordinates theta angle (left) and planes of acquisition (right) for geometry B

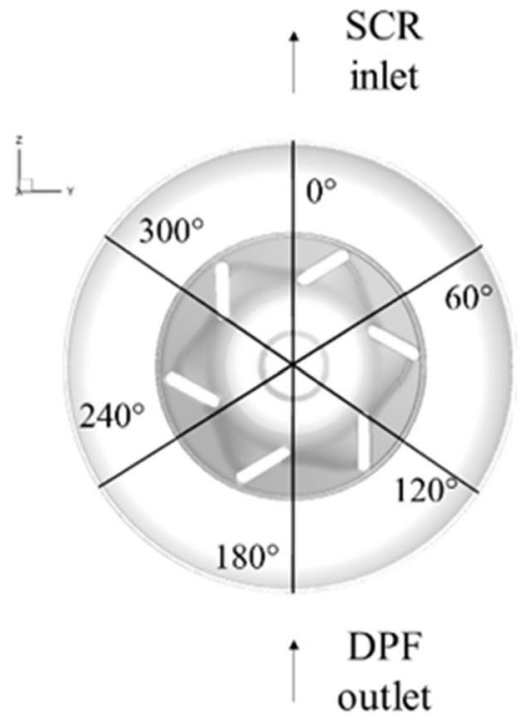

The computational domain was discretized with a base grid size of $5 \mathrm{~mm}$. To correctly characterize UWS spray and mixing phenomena, different grid refinements were implemented: firstly, fixed embedding has been placed along the UWS injector's hole axes, reaching a minimum grid size of $0.625 \mathrm{~mm}$. Then, an adaptive mesh refinement (AMR) technique has been applied (minimum grid size $0.625 \mathrm{~mm}$ ), to allow mesh refinements where high velocity and temperature gradients grew up.

The Reynolds-averaged Navier-Stokes (RANS) RNG $\boldsymbol{\kappa}-\boldsymbol{\epsilon}$ model [18] has been used to characterize the turbulence inside the system, as suggested in the case of a rotating flow [19]. The kinetic and thermal boundary layers have been described with a law-of-the-wall approach, and scalable wall functions have been implemented. The target for the near-wall cells $\boldsymbol{y}^{+}$was in the range of 30-150, obtained with the AMR technique. The O'Rourke and Amsden heat transfer model has been employed to account for turbulence heat transfer to the walls [20].

Regarding the liquid/gas coupling, Lagrangian and Eulerian approaches have been employed for the liquid and gas phases, respectively. Liquid AdBlue was simulated, with water and urea physical properties modeled as a function of temperature, using a specific size distribution for droplet initialization which was derived from the injector's manufacturer datasheet. A trapezoidal injection rate profile has been considered for UWS injection, with an injection frequency of $4 \mathrm{~Hz}$, and each injection duration is of about $24 \mathrm{~ms}$. A Kelvin-Helmholtz model [21] which was calibrated in a previous activity for a similar injector [22] has been adopted to account for droplets breakup. Other relevant settings adopted in 3D-CFD simulations were derived from [22] and are reported in Table 2.

\subsection{UWS Decomposition and Deposit Risk Evaluation}

The UWS decomposition could be modeled inside a 3D-CFD analysis through different methodologies. For example, simplified models describe only the process of urea thermolysis and hydrolysis using lumped reactions, while more elaborated models consider detailed urea reaction schemes and by-product formations [15]. Simplified models have been broadly applied confirming their validity in an extensive range of exhaust temperatures [29]; however, their main drawback is the lack of urea deposit formation predictiveness. To overcome this limitation, in the present work, a simplified model for the UWS decomposition has been used, the so-called Molten Solid approach [30], together with a user-defined deposit risk index derived from the work of Smith et al. [12]. In this way, an optimal balance between the computational cost needed by the UWS decomposition model and the correct characterization in terms of deposit risk on the mixer region has been obtained. Some details concerning the molten solid approach and the deposit risk index definition are given in the following paragraphs.

According to the molten solid approach, urea decomposition starts only after the complete evaporation of water from each UWS droplet. The decomposition of solid urea into gaseous ammonia and isocyanic acid is modeled with an Arrhenius equation, whose coefficients are obtained from [31]. In addition, hydrolysis of isocyanic acid is modeled using a dedicated reaction mechanism [32].

The numerical evaluation of the urea deposit formation risk in this study was based on an empirical approach, developed from an experimental campaign carried out by Smith 
Table 2 Summary of the spray and liquid film models implemented in the 3D-CFD simulations to simulate the UWS

\begin{tabular}{ll}
\hline Injected Liquid & Liquid AdBlue \\
\hline Urea model & Molten-solid urea model \\
Liquid injection & Customized injection size distribution \\
Spray breakup model & Calibrated KH model [21] \\
Evaporation model & Frossling model [23] \\
Droplet drag & Dynamic drop drag [24] \\
Collision model & NTC collision model [25] \\
Droplet turbulence dispersion & O' Rourke Turbulent dispersion [26] \\
Droplet/wall interaction & Calibrated Kuhnke wall film model \\
& [27] \\
Droplet/wall heat transfer & Wruck heat transfer model [28] \\
\hline
\end{tabular}

et al. to characterize the major factors influencing deposit formation [12]. According to Smith et al., the liquid film is mandatory for the formation of solid deposits, and its development could follow seven different paths. In particular, the progress of secondary reactions and the formation of species such as biuret, ammelide, and cyanuric acid leads to the formation of solid deposits. The formation of deposits is related to different conditions of liquid film thickness, velocity, temperature, and isocyanic local concentrations. In particular, liquid film thickness should be lower than a critical threshold to allow deposit formation, and film velocity should be higher than a critical value. In addition, film temperature should be higher than $160{ }^{\circ} \mathrm{C}$, since secondary reactions leading to deposits formation have been observed to become evident above this temperature during specific experiments. Nevertheless, HNCO concentrations in the gas flowing above the liquid film must be able to sustain reactions; therefore, a minimum isocyanic acid concentration threshold exists.

It should be noticed that, differently from Smith et al. [12], in this study liquid film having temperatures above 250 ${ }^{\circ} \mathrm{C}$ does not contribute to deposit formation, consistently with the Kuhnke wall film model, which describes liquid film deposition only below $250{ }^{\circ} \mathrm{C}$. In the present work, a dedicated subroutine has been developed to identify the liquid film development paths, based on the above-mentioned criteria, using a customized index. Liquid film developing towards the critical path has been used to identify the zones of the exhaust systems in which deposit formation is expected. Since the modeling methodology allowed the identification of the liquid film evolving towards the deposit formation path rather than the detailed description of solids by-products nucleation and growth, the customized index has been referred to as deposit formation risk index.

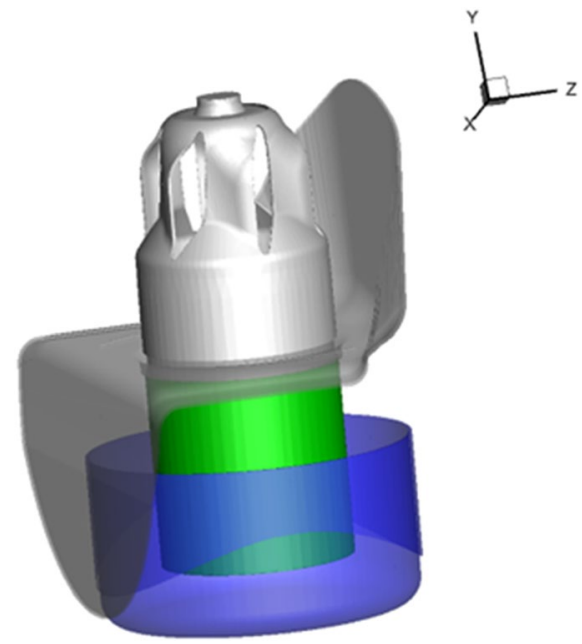

Fig. 9 Thermal boundaries characterization of geometry A, adiabatic walls in grey, 3D-CHT solid walls in green and 1D-CHT boundaries in blue

\subsection{Thermal Boundary Conditions and Conjugate Heat Transfer}

As far as thermal boundaries are concerned, different conditions were adopted along with the system. Adiabatic conditions were assumed for surfaces placed away from the UWS injection and mixing regions since thermal boundaries in these zones are expected to have a negligible impact on the 3D-CFD simulations results. On the contrary, a correct description of the temperature field in the mixer region is critical achieving realistic 3D-CFD results, since UWS impinging on solid walls contributes to their cooling and could cause liquid film formation, affecting not only the availability of $\mathrm{NH}_{3}$ at SCR inlet but also the formation of solid deposits within the exhaust systems.

A 3D-CHT simulation methodology is therefore mandatory to describe the evolution of gas, liquid, and solid temperatures in the mixer region. However, the computational cost associated with such analysis is significant and increases with the extensions of the solid mesh. To reduce as much as possible the computational effort associated with the CHT analysis, preliminary transient simulations were carried out with adiabatic walls to identify all the boundaries showing significant liquid film formation. The simulated time at this stage was coincident with a couple of injection periods.

Following the results of the preliminary analyses, a 3D solid mesh was created to describe the components showing significant liquid film formation, while other boundaries were modeled as adiabatic walls. Thin peripheral solids exposed to external insulation and showing liquid film 
formation, for which thermal penetration depth was considered small, were modeled using 1D-CHT boundary conditions. The latter consists in modeling heat transfer in thin solid thickness through a 1D thermal network, at the end of which on one side the gas temperature and heat transfer coefficient linked to the 3D-CFD simulation are imposed, and on the other side a bulk constant temperature is adopted (assumed equal to $250{ }^{\circ} \mathrm{C}$ in the present study).

The peripheral solids modeled using 1D-CHT boundary conditions were the plate placed between the wings in geometry A and the bell-shaped cup placed downstream of the injector in geometry B. Figure 9 shows an example of the different thermal boundaries adopted in the final simulation setup, for geometry B. The bottom section of the intermediate pipe placed downstream of the injector has been represented as a 3D solid region, for which CHT modeling is enabled (green surfaces). Furthermore, the downstream bell-shaped cup has been represented as a 1D-CHT boundary (blue surfaces).

Lastly, considering that the timescale of solid thermal dynamics is in the order of minutes, while the timescale of injection events is in the order of milliseconds, a conventional 3D-CFD transient simulation to describe steady-state system conditions was not feasible due to prohibitive computational costs. To overcome this issue, the super-cycling approach [17] has been used, which iterates between fullycoupled gas-solid transient and solid-only steady-state solvers, to speed up simulation convergence towards steady-state system thermal conditions. Further details concerning the super-cycling modeling strategy can be found in [17, 22].

In the present application, the super-cycling model has been applied for each $0.25 \mathrm{~s}$, starting in correspondence with the first injection event. Almost 40 UWS injection events have been simulated in the final transient simulations, used to assess system performance.

\subsection{Uniformity Index}

The distribution of the velocity and species concentration on a reference surface can be synthetically represented by the uniformity index (UI) calculation. In particular, it is known that in SCR applications, a high level of uniformity on catalyst inlet section is correlated to better performances in terms of $\mathrm{NO}_{\mathrm{x}}$ conversion [33]. In the present work, the definition of the uniformity index, $U I$, is based on the expression of Eq. (6), referred as an example of the velocity distribution on a selected section of interest:

$U I=1-\frac{1}{2} \sum_{i} \frac{A_{i}}{A_{\text {tot }}} \frac{\left|\overline{v_{i}}-\overline{v_{\text {avg }}}\right|}{\overline{v_{\text {avg }}}}$,

where $A_{i}$ is the face area of a single cell, $A_{t o t}$ is the total area of the considered section, $\bar{v}_{i}$ is the face value of the velocity in one single computational cell, and $\overline{v_{a v g}}$ is the surface average velocity on the considered section. Timeaveraged concentration and velocities are considered in the calculation, consistently with experimental procedures.

\section{Results and Discussion}

In this section, a comparison of the performance for the two exhaust designs is presented, and correlations between 3D-CFD simulation results and experimental campaign outcomes are highlighted. The operating condition selected is test case 1 of Table 1 , characterized by an exhaust mass flow rate of $125 \mathrm{~kg} / \mathrm{h}$ and a gas temperature of $250{ }^{\circ} \mathrm{C}$.

First, experimental $\mathrm{NO}_{x}$ conversion efficiencies are presented and compared to simulation results, to identify the root causes of the different performances characterizing the two exhaust designs. Systems' $\mathrm{NO}_{\mathrm{x}}$ conversion response times are then analyzed, and the outcomes of experimental and numerical activities are compared. Lastly, images acquired within the system at the end of experimental tests are compared to simulation results representing the risk of deposit formation, to investigate the predictivity and the limitations of the numerical methodology.

\section{1 $\mathrm{NO}_{\mathrm{x}}$ Conversion Efficiency}

The time-averaged $\mathrm{NO}_{\mathrm{x}}$ conversion efficiencies of the two systems have been measured during experimental tests and are shown in Fig. 10. Both systems show conversion efficiencies above 97\%; however, geometry A configuration shows higher $\mathrm{NO}_{\mathrm{x}}$ conversion capabilities compared to geometry $\mathrm{B}(+1.2 \%)$.

Among the possible causes for the performance differences of the two systems, it is possible to mention the role of $\mathrm{NH}_{3}$ distribution upstream of the SCR filter: a non-uniform $\mathrm{NH}_{3}$ distribution on the SCR inlet section can result in excessive local ammonia concentration and a consequent ammonia slip for specific channels of the filter. On the contrary, an insufficient local ammonia concentration in other zones of the filter leads to a reduced $\mathrm{NO}_{\mathrm{x}}$ conversion. In this context, $\mathrm{NH}_{3}$ distribution measured upstream of the SCR filters in 3D-CFD simulations was found in good correlation with experimental results concerning steady-state $\mathrm{NO}_{\mathrm{x}}$ conversion efficiencies. In Fig. 11, a comparison between $\mathrm{NH}_{3}$ distribution at SCR filter inlet section for design geometry A (left) and geometry B (right) is presented. Significant differences characterize $\mathrm{NH}_{3}$ distribution for the two systems: geometry A has an almost uniform $\mathrm{NH}_{3}$ distribution on the SCR inlet section, leading to a uniformity index equal to 0.98 , while geometry $\mathrm{B}$ shows a local variation of $\mathrm{NH}_{3}$ concentration; therefore, a uniformity index equal to 0.96 is achieved. Overall, differences in $\mathrm{NH}_{3}$ uniformity indexes for geometry A and geometry B $(+2 \%)$ are in good 
correlation with discrepancies observed in experimental steady-state $\mathrm{NO}_{\mathrm{x}}$ conversion efficiency for the two exhaust lines $(+1.2 \%)$. As far as uniformity indexes of velocities are concerned, no significant differences have been found between the results of the two systems.

Other possible causes for differences in steady-state $\mathrm{NO}_{\mathrm{x}}$ reduction performance for the two systems could be ascribed to urea-to- $\mathrm{NH}_{3}$ conversion efficiencies. However, experiments, as well as numerical simulations, highlighted that urea-to- $\mathrm{NH}_{3}$ conversion affects initial system performance rather than steady-state $\mathrm{NO}_{\mathrm{x}}$ reduction. The ramp-up of $\mathrm{NO}_{\mathrm{x}}$ conversion efficiencies after the first UWS injection event was investigated experimentally and is shown in the upper part of Fig. 12 for geometry A (black curve) and geometry B (red curve). Geometry B is characterized by a very small system response time, as the red curve suddenly increases to $40 \%$ conversion efficiency almost instantly after the start

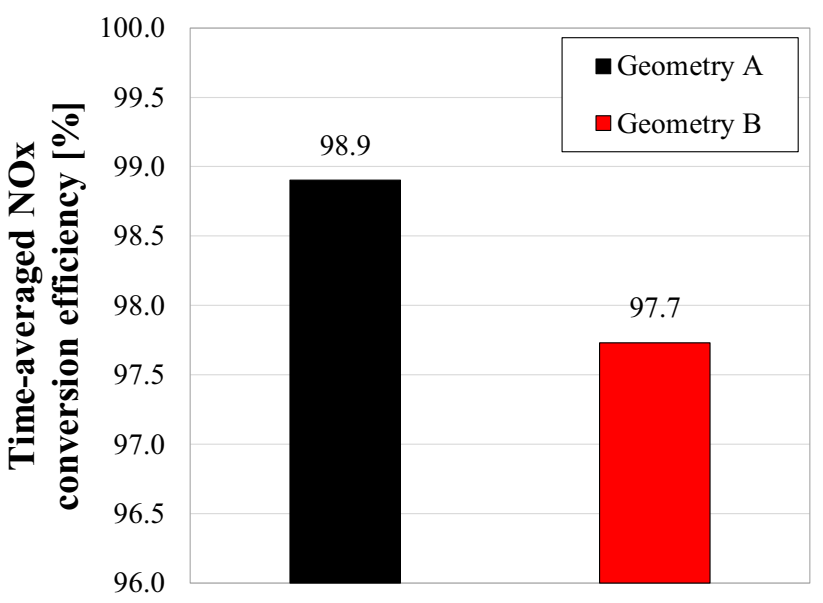

Fig. 10 Global $\mathrm{NO}_{\mathrm{x}}$ conversion efficiency obtained from the experimental tests on geometry $\mathbf{A}$ and $\mathbf{B}$

of UWS injection, while $\mathrm{NO}_{\mathrm{x}}$ conversion for geometry $\mathrm{A}$ is affected by a delay of about $20 \mathrm{~s}$. The conversion efficiency curves tend to converge afterward and reach the same value roughly $80 \mathrm{~s}$ after the start of the UWS injection. Going ahead, both systems reach their steady-state conversion efficiency roughly $200 \mathrm{~s}$ after the start of UWS injection, consistently with the mean value of Fig. 10. The bar chart indented in the upper part of Fig. 12 shows the time-averaged $\mathrm{NO}_{\mathrm{x}}$ conversion efficiencies measured experimentally during the first $200 \mathrm{~s}$ after the start of UWS injection. The better performance achieved with geometry B is evident: the average conversion efficiency is equal to $83.7 \%$ compared to $80.7 \%$ of geometry A $(+3 \%)$, thanks to the reduced system response time.

Similar information can be obtained from 3D-CFD results: it was found that calculated urea-to- $\mathrm{NH}_{3}$ conversion efficiency is the main factor differentiating the performance of the two systems after the first injection events, as shown in the bottom part of Fig. 12 where calculated $\mathrm{NH}_{3}$ gas flow rates are represented during the first $7 \mathrm{~s}$ of the simulations. It is worth highlighting that the simulation time interval is not directly comparable to the experimental one due to the adoption of the super-cycling strategy in 3D-CFD simulations; therefore, 7 seconds in simulations are representative of significantly longer experimental times. Figure 12 shows that geometry B (red curve) has a negligible system response time as it provides ammonia at the SCR inlet section already during the very first injection event, differently than geometry A (black curve) which shows a delay. In addition, geometry B provides a higher $\mathrm{NH}_{3}$ flow rate compared to geometry A during the time interval shown in Fig. 12, and this is in good correlation with the higher average experimental $\mathrm{NO}_{\mathrm{x}}$ conversion efficiency measured during the first $200 \mathrm{~s}$ after the start of UWS injection (Fig. 12, top).

Additionally, the rate of increase of ammonia flow rate for geometry $\mathrm{A}(\alpha)$ is higher compared to geometry $\mathrm{B}(\beta)$; therefore, the two systems are expected to reach the same ammonia availability on the SCR inlet section after a certain time interval. This is in good agreement with Fig. 12 (top) showing that the same $\mathrm{NO}_{\mathrm{x}}$ conversion efficiencies for the two systems are reached $80 \mathrm{~s}$ after the start of UWS injection.

Therefore, the phenomenology observed in 3D-CFD simulations suggests that urea-to- $\mathrm{NH}_{3}$ conversion efficiency is the main factor influencing $\mathrm{NO}_{\mathrm{x}}$ conversion efficiency during the initial transient operation of the two SCR systems, while the driving factor affecting performance becomes the $\mathrm{NH}_{3}$ distribution upstream of catalyst section when steady-state operating conditions are reached.

\subsection{Urea Deposit Location}

As far as deposits are concerned, 3D-CFD simulations performed in this study provide information concerning the risk of deposit formation rather than the exact location of deposit nuclei and their growth rate or disappearance over time. The risk of deposit formation is highly influenced by spray development and droplet-wall interactions, as well as wall cooling. In this context, Fig. 13 represents the UWS spray evolution inside the two different mixer subsystems and the corresponding droplets sizes, while Figs. 14 and 15 show the zones of geometry A and B, respectively, in which there is a high risk of deposit formation according to numerical simulations.

It can be noticed from Fig. 13 that the spray development differs significantly between the two systems under study. In particular, even if the behavior of the droplets is similar near the tip of the nozzle, the distribution of droplets sizes along the remaining part of the spray is significantly different. Figure 13 shows that most of the small droplets tend to vanish 
Fig. $11 \mathrm{NH}_{3}$ distribution at SCR inlet section obtained in 3D-CFD simulation for geometry $\mathbf{A}$ (left) and geometry B (right)
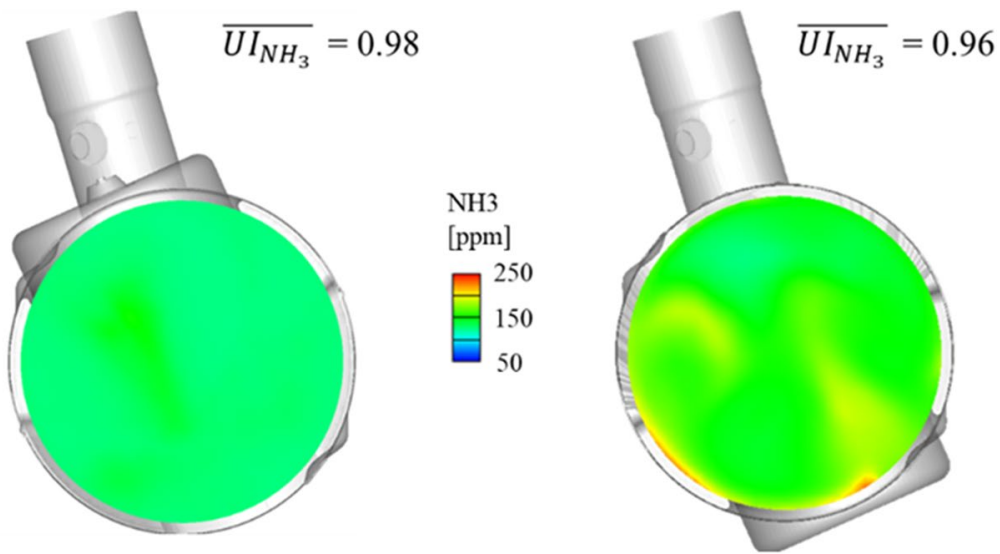

downstream of the injection pipe for Geometry A, while they are still present at the tip of the spray for Geometry B. Droplet breakup and evaporation rate are therefore different between the two systems, as well as the transport of droplets by the gas flow; therefore, different liquid-wall interactions and deposit formation risks can be expected.
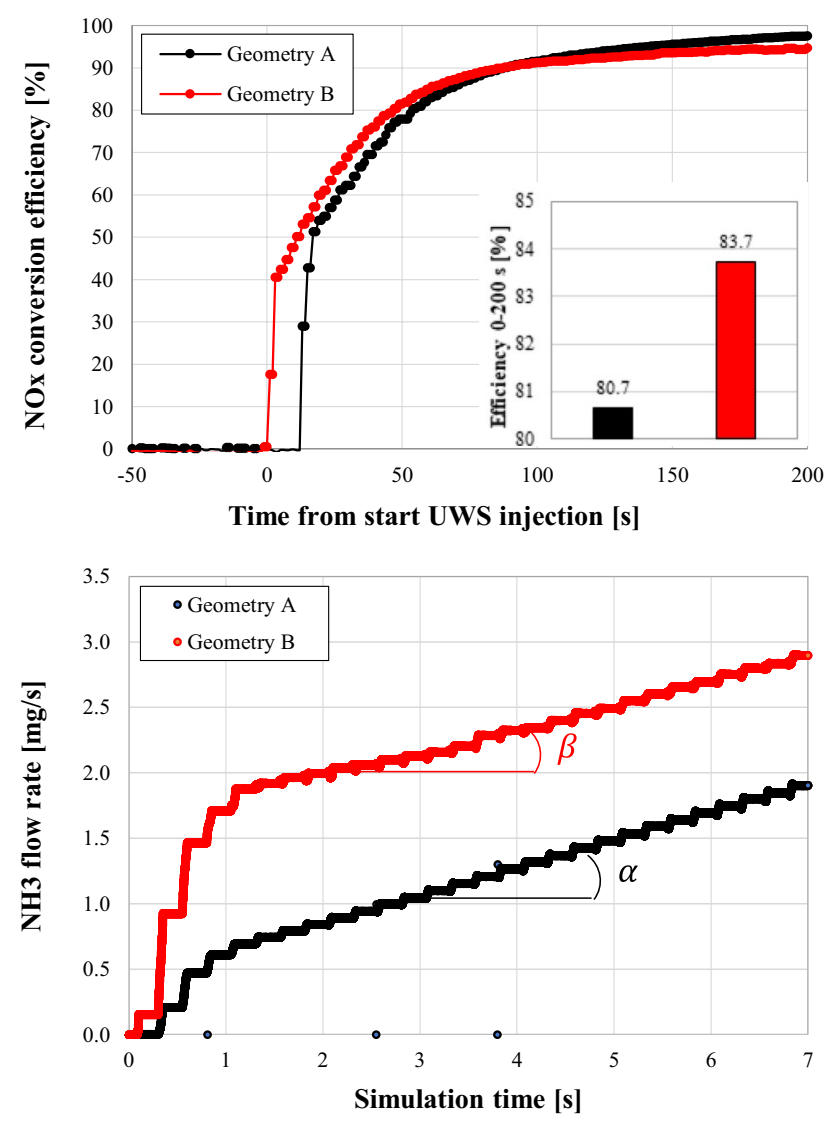

Fig. 12 System response time. Top: $\mathrm{NO}_{\mathrm{x}}$ conversion efficiency from the experimental test in the period $0.200 \mathrm{~s}$. Bottom: $\mathrm{NH}_{3}$ mass flow through SCR inlet from numerical analysis
Figure 14 shows that the deposit formation risk for geometry A is present along most of the intermediate pipe placed between the wings and the injector, in addition to the wings, where the spray interacts with walls and creates a liquid film. Injector's holes axes point towards the surface placed between the swirl-inducing wings (see Fig. 13); therefore, an injection in quiescent conditions would result in negligible impingement of liquid droplets with intermediate pipe and wings' surfaces. The swirling gas flow created by the wings, however, moves within the pipe towards the injector and tends to increase the spray angle because of centrifugal forces, in addition to the effect given by gas and spray opposite directions. The counterflow configuration enhances spray breakup and the resulting small droplets are transported towards surrounding walls, thanks to their reduced inertia (see Fig. 13, left). As a result, the main spray impingement zone is still located on the surface separating the two wings, while an additional distributed spray impact zone exists on both wings as well as on the intermediate pipe, where droplets are transported by gas dynamics and turbulent dispersion. The droplets impinging on pipe walls and wings evaporate quickly and create local low-temperature spots, which allow liquid film formation during consecutive injections. The liquid film created in these zones is transported by shear effects due to gas motion, in addition to gravity, and hence is characterized by small velocities since it is localized outside of the main spray impingement area. Additionally, liquid film transported outside of droplet impingement zones on pipe walls and wings is heated up by adjacent walls and reaches temperatures above 160 ${ }^{\circ} \mathrm{C}$, which is considered the minimum temperature below which fast urea decomposition and secondary reactions leading to deposit formation are not observed. Lastly, the local concentration of $\mathrm{HNCO}$ in the gas flowing above the liquid film, in combination with reduced liquid film dynamics and high temperatures, is sufficient to trigger the formation of deposits according to simulation results, which justify the localization of the red areas in Fig. 14. 
Fig. 13 Instantaneous UWS spray evolution and droplet size distribution obtained with the 3D-CFD simulations. Left: geometry A, right: geometry $\mathbf{B}$

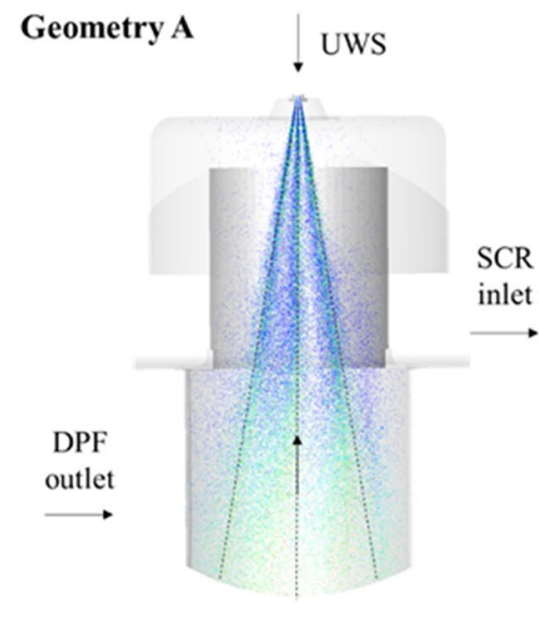

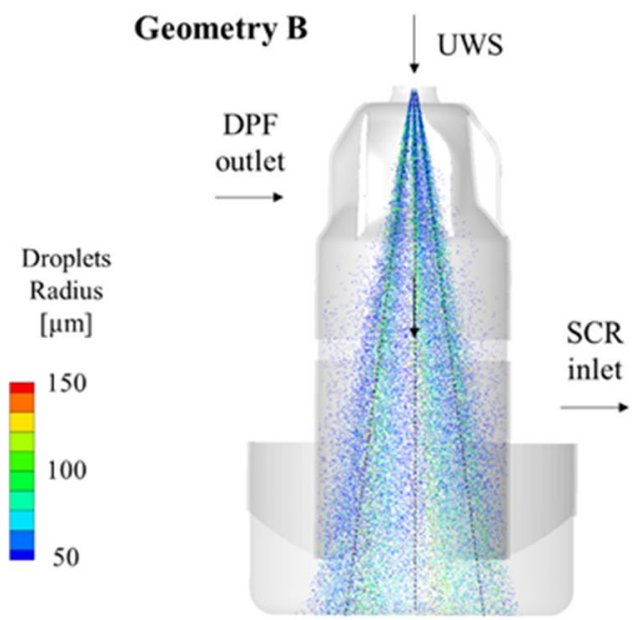

Considering the described phenomenology, the formation of several deposit nuclei is expected on wings and intermediate pipe' surfaces, rather than the formation of a single solid cluster. It is however possible that adjacent solid deposits grow during consecutive injections up to the point that several solid clusters are obtained because of the merging, an aspect which is currently not described by the simulation methodology adopted in the study. Lastly, no significant deposit risk is expected for surfaces placed downstream of the intermediate pipe, according to Fig. 14.

The area of geometry B exhaust line showing high deposit formation risk, on the contrary, has limited extension compared to geometry A, as shown in Fig. 15. The root causes for this difference are linked to the peculiar characteristics of spray and gas development in geometry B: in this case, gas flow and liquid spray move in the same direction downstream of the radial mixer (see Fig. 13, right). In particular, the swirling gas flow is created by the openings characterizing the radial mixer design, which drives the gas in a circumferential direction around the injector axis. The resulting gas velocity field in the mixer and pipe's cross-sections is similar to that of a rotating disk, as tangential velocities increase in a radial direction when moving from the injector's axis to the pipe's walls. UWS injection takes place at the center of the rotating gas flow field; therefore, a negligible impact of gas velocity is observed on the spray development during initial droplet penetration. Since droplets move radially towards the pipe's walls as their penetration increases, effects due to the swirling gas increase and result in a wider spray angle and an enhanced spray breakup for the periphery of the spray. The distance from the injector's holes at which the centrifugal forces prevail on droplets inertia is increased compared to geometry A; therefore, the area of the intermediate pipe on which small droplets are transported is significantly reduced (see Fig. 13).

The local formation and transportation of liquid film rivulets, in addition to the combination of limited film dynamics, a temperature higher than $160{ }^{\circ} \mathrm{C}$ and $\mathrm{HNCO}$ availability, lead to the risk of deposit formation in the final part of the intermediate pipe, as shown in Fig. 15. Large droplets, which are less likely to be deviated by the swirling gas field, reach the surface of the bell-shaped cup placed at the exit of the intermediate pipe and create a ring-shaped continuous liquid film. This liquid film moves away from the impact zones in a radial direction, due to shear forces induced by the gas moving in the same direction. Deposit formation is predicted in this zone due to the combination of relatively high wall temperatures, $\mathrm{HNCO}$ availability, and reduced film dynamics. Lastly, droplets having intermediate sizes remain suspended

Fig. 14 3D-CFD boundaries showing a risk of deposit formation, geometry A

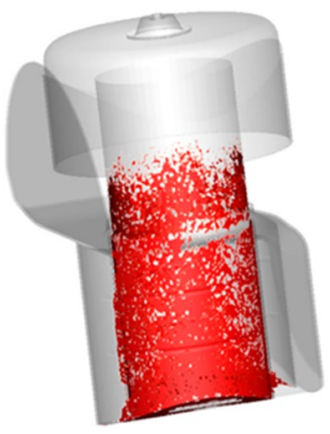

Fig. 15 3D-CFD boundaries showing a risk of deposit formation, geometry B

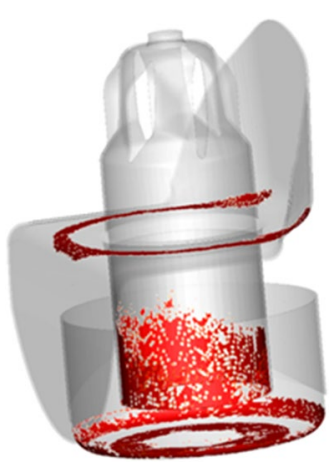


within the flowing gas until they reach the outer part of the intermediate pipe. In this zone, part of the droplets is centrifugated towards the sides of the bell-shaped cup during the inversion of gas flow direction, while the remaining droplets create a ring-shaped liquid film on the downstream plate, as shown in Fig. 15. Again, the deposit formation risk is related to the zones in which liquid film is transported after its initial formation, where reduced dynamics, sufficient temperature, and HNCO concentration are observed.

Figures 16 and 17 show a comparison between images acquired after experimental tests on the real systems and 3D-CFD results, therefore allowing a partial validation of simulation outcomes concerning deposit formation. In experimental images, the border of deposit clusters has been highlighted in red for visualization purposes, and the same color has been used to represent the deposit formation zones calculated in numerical simulations. Figure 16 shows results concerning deposit formation in geometry
A exhaust line at two specific distances from the injector tip $(50 \mathrm{~mm}$ and $109 \mathrm{~mm}$ ). Experimental data acquired at $50 \mathrm{~mm}$ from injector tip show the presence of significant deposit clusters at $120^{\circ}$ and $180^{\circ}$ orientations (first row of images in Fig. 16), information which is in good agreement with 3D-CFD results since the calculated deposit formation risk index is localized in the same positions (third row of images in Fig. 16). At $109 \mathrm{~mm}$ from the injector tip, the experimental images highlight the presence of deposits distributed among all the periphery of the intermediate pipe surface, as shown by the red curves in the second row of images in Fig. 16. 3D-CFD results (fourth row of images in Fig. 16) are again in good agreement with experimental data, even if a broader dispersion of the deposit formation risk index can be noticed, compared to experimental images. This is possibly a consequence of the numerical methodology in which the description of the growth of solid nuclei during consecutive injections and the merging
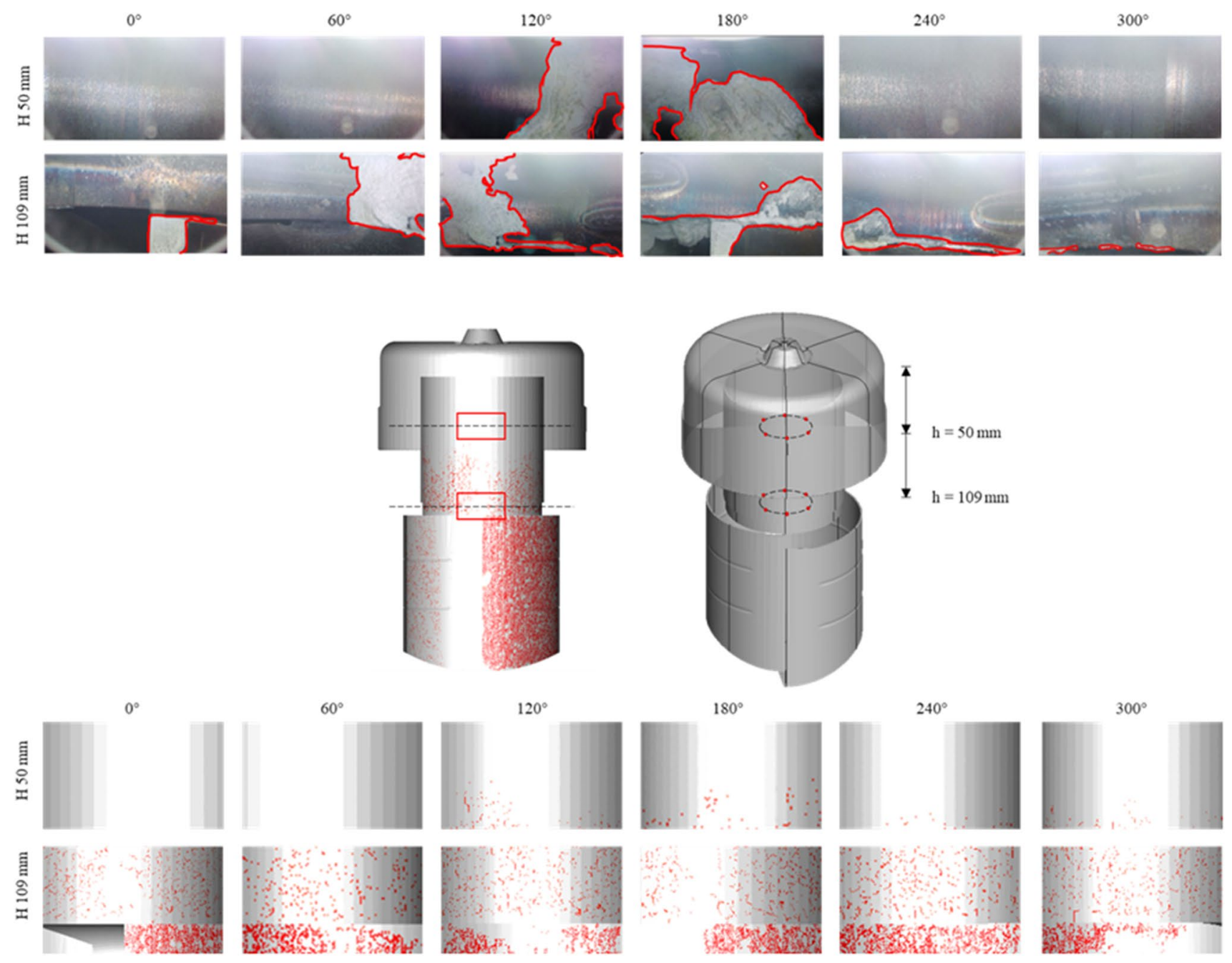

Fig. 16 Experimental acquisition of urea deposit (top) and simulated deposit risk (bottom) in geometry A exhaust line configuration, for several camera distances and orientations 

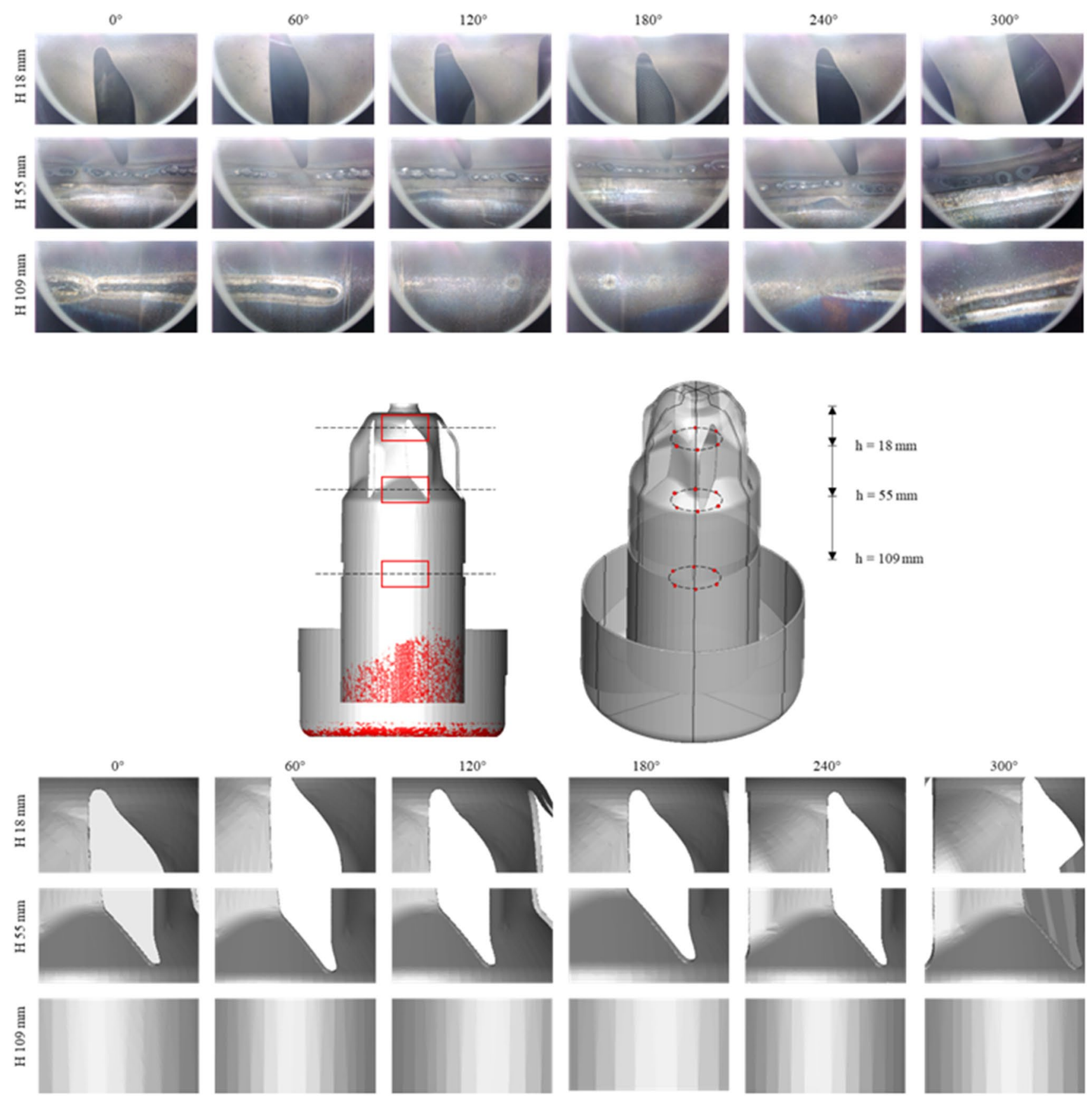

Fig. 17 Experimental acquisition of urea deposit (top) and simulated deposit risk (bottom) in geometry B exhaust line configuration, for several camera distances and orientations

of adjacent deposits is currently lacking. 3D-CFD results show significant deposit formation risk on the wings placed upstream of the intermediate pipe, as partially shown by the bottom part of the fourth row of images in Fig. 16; however, experimental data do not have sufficient backlight to allow further confirmation. Lastly, experimental data concerning distances higher than $109 \mathrm{~mm}$ from the injector tip were not available due to constraints related to the equipment used for image acquisition.
Figure 17 shows results concerning deposit formation in geometry B exhaust line at three distances from the injector tip (18 mm, $55 \mathrm{~mm}$, and $109 \mathrm{~mm}$ ). In this case, no deposits are observed in experimental images for all the different distances and orientations of the camera, thus confirming simulation outcomes that do not identify deposit formation risk in the same zones of the intermediate pipe. Experimental constraints bound the investigation of deposit formation to the upper part of the intermediate pipe also for geometry 
B pipe; therefore, no additional validation is available for the deposit formation zones calculated downstream along geometry B.

\section{Conclusions}

In this work, two configurations of an exhaust system for an off-road diesel engine have been analyzed, referred as to system A and system B. Both the systems are composed of a diesel oxidation catalyst (DOC) followed by a diesel particulate filter (DPF), and a selective catalytic reduction (SCR) component and differ only in the injection and mixing subsystem placed at the inlet of the Urea-SCR catalyst. A combined approach based on an experimental and numerical analysis has been developed, to characterize the system in terms of $\mathrm{NO}_{\mathrm{x}}$ conversion efficiency and urea deposit formation.

The two systems have been experimentally tested at three different operating conditions, varying the exhaust mass flow rate and temperature, while the results analyzed here are focused on one operating point $(150 \mathrm{~kg} / \mathrm{h}$ of exhaust mass flow rate and $250{ }^{\circ} \mathrm{C}$ of temperature) at which the numerical analysis has been also carried out, chosen as one of the most challenging for the present system configuration in terms of exhaust temperature among the ones tested experimentally. In particular, the experimental campaign highlighted high levels of steady-state $\mathrm{NO}_{\mathrm{x}}$ conversion efficiency, above $97.5 \%$ for both the geometries, while a slight discrepancy between the two systems has been detected $(+1.2 \%$ of efficiency for system A). A detailed analysis carried out in 3D-CFD simulations highlighted a more uniform distribution of $\mathrm{NH}_{3}$ at the SCR inlet section for system A, suggesting that this is the main factor characterizing better catalyst performances in $\mathrm{NO}_{\mathrm{x}}$ abatement for steady-state operating conditions. On the contrary, system B presented a faster response time in the first $0-200 \mathrm{~s}$ of the experimental test, correlated with a higher $\mathrm{NH}_{3}$ mass flow rate at the SCR inlet observed in the numerical analysis. Consequently, the urea-to- $\mathrm{NH}_{3}$ conversion efficiency seemed one of the driving factors influencing the NOx abatement in the initial transient operation mode.

A conjugate heat transfer (CHT) approach has been included in the 3D-CFD analysis to correctly describe the temperature distribution on the mixer walls, enabling the definition of a deposit risk index based on the liquid film properties, to assess the areas where the depositions are expected. The predictiveness of the deposit risk index has been validated through a comparison with internal pictures acquired after the experimental tests on both the geometries by an endoscopic analysis, showing a good agreement between the area highlighted in the simulation at high risk of deposit formation and the real mixer walls where the deposits were clearly visible.

In conclusion, a complementary approach based on experimental testing and simulation analysis has been developed and adopted to investigate the main factors influencing the SCR catalyst performance and the root causes of deposit formation, with a consequent optimization of the urea water spray (UWS) mixer geometry. The presented coupled analysis showed good results, albeit further numerical investigations are needed to validate the methodology concerning urea deposit formation risk at different engine operating conditions.

Abbreviations AMR: Adaptive mesh refinement; ATS: Aftertreatment system; CFD: Computational fluid dynamics; CHT: Conjugate heat transfer; DEF: Diesel exhaust fluid; DOC: Diesel oxidation catalyst; DPF: Diesel particulate filter; HFB: Hot flow bench; $\mathrm{NO}_{\mathrm{x}}$ : Nitrogen oxides; OEM: Original equipment manufacturer; PM: Particulate matter; RANS: Reynolds-averaged navier-stokes; RDE: Real driving emission; SCR: Selective catalytic reduction; UWS: Urea-water-solution; UI: Uniformity index; $\mathbf{N H}_{\mathbf{3} \text {,act }}$ : Actual stored $\mathrm{NH}_{3}$ mass, g; $\mathbf{N H}_{\mathbf{3} \text {,in }}$ : Mean $\mathrm{NH}_{3}$ flow converted during the efficiency test, mol/s; $\mathbf{N H}_{\mathbf{3} \text {,inj }}: \mathrm{NH}_{3}$ flow theoretically entering the system in form of urea, mol/s; $\mathbf{N H}_{3, \text { miss }}: \mathrm{NH}_{3}$ not present at the SCR outlet, ppm; $\boldsymbol{N H}_{3, \text { out }}: \mathrm{NH}_{3}$ concentration measured at the SCR system outlet, ppm; $\mathbf{N H}_{3, \mathrm{th}}$ : Theoretical stored $\mathrm{NH}_{3}$ mass, g; $\mathbf{N H}_{3 \text {,usedentersion }} \mathrm{NH}_{3}$ theoretical concentration that reacts with $\mathrm{NO}_{x}, \mathrm{ppm} ; \boldsymbol{N \boldsymbol { O } _ { x }}$, in: $\mathrm{NO}_{x}$ concentration (as sum of $N O$ and $N O_{2}$ ) at the SCR system inlet, ppm; $\boldsymbol{N \boldsymbol { O } _ { \boldsymbol { x } }}$, out: $\mathrm{NO}_{\mathrm{x}}$ concentration (as sum of $\mathrm{NO}$ and $\mathrm{NO}_{2}$ ) at the SCR system outlet, ppm; $\bar{n}_{\text {air }}$ : Airflow rate, $\mathrm{mol} / \mathrm{s} ;$ Eff: $\mathrm{NO}_{\mathrm{x}}$ reduction efficiency, n.d.

Acknowledgements Computational resources were provided by HPC@POLITO, the Academic Computing Center of Politecnico di Torino (http://hpc.polito.it).

Author Contribution Conceptualization: Federico Millo, Lucio Postrioti, Andrea Bianco; methodology: Lucio Postrioti, Andrea Bianco; Software: Andrea Bianco, Francesco Sapio, Benedetta Peiretti Paradisi, Cristina Robino; validation: Giacomo Buitoni, Marco Tabarrini; formal analysis and investigation: Andrea Bianco, Francesco Sapio, Benedetta Peiretti Paradisi; writing — original draft preparation: Benedetta Peiretti Paradisi; writing — review and editing: Federico Millo, Lucio Postrioti, Andrea Bianco; funding acquisition: Federico Millo, Cristina Robino; supervision: Federico Millo, Lucio Postrioti, Andrea Bianco. All authors have read and agreed to the published version of the manuscript.

\section{Declarations}

Competing Interests The authors declare no competing interests.

Open Access This article is licensed under a Creative Commons Attribution 4.0 International License, which permits use, sharing, adaptation, distribution and reproduction in any medium or format, as long as you give appropriate credit to the original author(s) and the source, provide a link to the Creative Commons licence, and indicate if changes 
were made. The images or other third party material in this article are included in the article's Creative Commons licence, unless indicated otherwise in a credit line to the material. If material is not included in the article's Creative Commons licence and your intended use is not permitted by statutory regulation or exceeds the permitted use, you will need to obtain permission directly from the copyright holder. To view a copy of this licence, visit http://creativecommons.org/licenses/by/4.0/.

\section{References}

1. Koebel, M., Elsener, M., Kleemann, M.: Urea-SCR: a promising technique to reduce NOx emissions from automotive diesel engines. Catal. Today. 59, 335-345 (2000). https://doi.org/10. 1016/S0920-5861(00)00299-6

2. Dörnhöfer, J., Börnhorst, M., Ates, C., Samkhaniani, N., Pfeil, J., Wörner, M., Koch, R., Bauer, H.J., Deutschmann, O., Frohnapfel, B., Koch, T.: A holistic view on urea injection for nox emission control: impingement, re-atomization, and deposit formation. Emiss. Control Sci. Technol. 6(2), 228-243 (2020). https://doi. org/10.1007/s40825-019-00151-0

3. Eakle, S., Kroll, S., and Henry, C.: Investigation of urea derived deposits composition in SCR systems. SAE Technical Paper 201601-2327. (2016). https://doi.org/10.4271/2016-01-2327

4. Postrioti, L., Brizi, G., Ungaro, C., Mosser, M., Bianconi, F.: A methodology to investigate the behaviour of urea-water sprays in high temperature air flow for SCR de-NOx applications. Fuel. 150, 548-557 (2015). https://doi.org/10.1016/j.fuel.2015.02.067

5. Betageri, V., Rajagopalan, M., Dhakshina Murthy, S., Thondavadi, A.: Effects of diesel exhaust fluid (DEF) injection configurations on deposit formation in the SCR system of a diesel engine. SAE Technical Paper 2016-28-0109. (2016). https://doi.org/10.4271/ 2016-28-0109

6. Liao, Y., Dimopoulos Eggenschwiler, P., Rentsch, D., Curto, F., Boulouchos, K.: Characterization of the urea-water spray impingement in diesel selective catalytic reduction systems. Appl. Energy. 205, 964-975 (2017). https://doi.org/10.1016/j.apenergy. 2017.08.088

7. Varna, A., Spiteri, A.C., Wright, Y.M., Dimopoulos Eggenschwiler, P., Boulouchos, K.: Experimental and numerical assessment of impingement and mixing of urea-water sprays for nitric oxide reduction in diesel exhaust. Appl. Energy. 157, 824-837 (2015). https://doi.org/10.1016/j.apenergy.2015.03.015

8. Yi, Y.: Development of a 3D numerical model for predicting spray, urea decomposition and mixing in SCR systems. SAE Technical Paper 2007-01-3985. (2007). https://doi.org/10.4271/ 2007-01-3985

9. Way, P., Viswanathan, K., Preethi, P., Gilb, A., Zambon, N., and Blaisdell, J.: SCR performance optimization through advancements in aftertreatment packaging. SAE Technical Paper 200901-0633. (2009). https://doi.org/10.4271/2009-01-0633

10. Zheng, G., Palmer, G., Salanta, G., and Kotrba, A.: Mixer development for urea SCR applications. SAE Technical Paper 200901-2879. (2009). https://doi.org/10.4271/2009-01-2879

11. Zheng, G., Fila, A., Kotrba, A., and Floyd, R.: Investigation of urea deposits in urea SCR systems for medium and heavy duty trucks. SAE Technical Paper 2010-01-1941. (2010). https://doi. org/10.4271/2010-01-1941

12. Smith, H., Lauer, T., Mayer, M., Pierson, S.: Optical and numerical investigations on the mechanisms of deposit formation in SCR systems. SAE Int. J. Fuels Lubr. 7(2), 525-542 (2014). https://doi. org/10.4271/2014-01-1563
13. Habchi, C., Quan, S., Drennan, S., and Bohbot, J.: Towards quantitative prediction of urea thermo-hydrolysis and deposits formation in exhaust selective catalytic reduction (SCR) systems. SAE Technical Paper 2019-01-0992. (2019). https://doi.org/10.4271/ 2019-01-0992

14. Huang, H., Chen, Y., Li, Z., Wang, H., Hao, B., Chen, Y., Lei, H., and Guo, X.: Analysis of deposit formation mechanism and structure optimization in urea-SCR system of diesel engine. Fuel. 265 (2020). https://doi.org/10.1016/j.fuel.2019.116941

15. Budziankou, U., Börnhorst, M., Kuntz, C., Deutschmann, O., Lauer, T.: Deposit formation from urea injection: a comprehensive modeling approach. Emiss. Control Sci. Technol. 6(2), 211-227 (2020). https://doi.org/10.1007/s40825-020-00159-x

16. Zheng, G.: CFD Modeling of urea spray and deposits for SCR systems. SAE Technical Paper 2016-01-8077. (2016). https://doi. org/10.4271/2016-01-8077

17. Richards, K.J., Senecal, P.K., Pomraning, E.: Converge 2.4. Converge Science Madison, WI (2018)

18. Orszag, S.A., Yakhot, V., Flannery, W.S., Boysan, F., Choudhury, D., Maruzewski, J., Patel, B.: Renormalization group modeling and turbulence simulations. Near-Wall Turbul. Flows 1031-1046 (1993)

19. Papageorgakis, G.C., Assanis, D.N.: Comparison of linear and nonlinear rng-based k-epsilon models for incompressible turbulent flows. Numer. Heat Transf. Part B Fundam. 35(1), 1-22 (1999). https://doi.org/10.1080/104077999275983

20. Amsden, A.A.: KIVA-3V: a block-structured KIVA program for engines with vertical or canted valves. Los Alamos Natl. Lab. LA-13313-MS. (1997)

21. Reitz, R.D., Bracco, F.: Mechanisms of breakup of round liquid jets. Encycl. Fluid Mech. 3, 233-249 (1986)

22. Sapio, F., Millo, F., Fino, D., Monteverde, A., Sartoretti, E., Bianco, A., Postrioti, L., Tarabocchia, A., Buitoni, G., Brizi, G.: Experimental and numerical analysis of latest generation diesel aftertreatment systems. SAE Technical Paper 2019-24-0142. (2019). https://doi.org/10.4271/2019-24-0142

23. Amsden A.A., O’Rourke P.J., Butler T.D., I.K.: A computer program for chemically reactive flows with sprays. Los Alamos Natl. Lab. Rep. LA-11560-MS.(1989)

24. Liu, A.B., Mather, D., and Reitz, R.D.: Modeling the effects of drop drag and breakup on fuel sprays. SAE Technical Paper 930072. (1993). https://doi.org/10.4271/930072

25. Schmidt, D.P., Rutland, C.J.: A new droplet collision algorithm. J. Comput. Phys. 164(1), 62-80 (2000). https://doi.org/10.1006/ jcph.2000.6568

26. Amsden, A., O'Rourke, P., Butler, T.: KIVA-II: a computer program for chemically reactive flows with sprays, Technical Report LA-11560-MS, UC-96. Los Alamos Natl. Lab. (1989)

27. Kuhnke, D., "Spray/wall-interaction modelling by dimensionless data analysis," ISBN 3-8322-3539-6, (2004).

28. Wruck, N.M. and Renz, U., "Transient phase-change of droplets impacting on a hot wall," Transient Phenom. Multiph. Multicomponent Syst., (2007), https://doi.org/10.1002/9783527610785. ch14

29. Ström, H., Lundström, A., Andersson, B.: Choice of urea-spray models in CFD simulations of urea-SCR systems. Chem. Eng. J. 150(1), 69-82 (2009). https://doi.org/10.1016/j.cej.2008.12.003

30. Quan, S., Wang, M., Drennan, S., Strodtbeck, J., and Dahale, A.: A molten solid approach for simulating urea-water solution droplet depletion. Institute for Liquid Atomization and Spray SystemsAmericas. (2015).

31. Birkhold, F., Meingast, U., Wassermann, P., Deutschmann, O.: Modeling and simulation of the injection of urea-water-solution 
for automotive SCR DeNOx-systems. Appl. Catal. B Environ. 70(1-4), 119-127. (2007). https://doi.org/10.1016/j.apcatb.2005. 12.035

32. Yim, S.D., Kim, S.J., Baik, J.H., Nam, I.S., Mok, Y.S., Lee, J.H., Cho, B.K., Oh, S.H.: Decomposition of urea into NH3 for the SCR process. Ind. Eng. Chem. Res. 43(16), 4856-4863 (2004). https:// doi.org/10.1021/ie034052j
33. Munnannur, A., Cremeens, C.M., Liu, Z.G.: Development of flow uniformity indices for performance evaluation of aftertreatment systems. SAE Int. J. Engines. 4(1), 1545-1555 (2011). https://doi. org/10.4271/2011-01-1239

Publisher's Note Springer Nature remains neutral with regard to jurisdictional claims in published maps and institutional affiliations. 